\title{
Monitoring moisture movements in building materials using X-ray attenuation: Influence of beam-hardening of polychromatic X-ray photon beams
}

\author{
Brad J. Pease $\mathrm{a}^{\mathrm{a}, *}$, Gregor A. Scheffler ${ }^{\mathrm{b}}$, Hans Janssen ${ }^{\mathrm{c}}$ \\ ${ }^{a}$ Technical University of Denmark (DTU), Department of Civil Engineering, Brovej - Building 118, DK-2800 Kgs. Lyngby, Denmark \\ ${ }^{b}$ Xella Technologie- und Forschungsgesellschaft, Hohes Steinfeld 1, 14797 Kloster Lehnin, Germany \\ ${ }^{c}$ Building Physics Section, Department of Civil Engineering, KU Leuven, Kasteelpark Arenberg 40, B-3001 Heverlee, Belgium
}

\begin{abstract}
X-ray attenuation measurements are commonly used as a non-destructive method to monitor internal concentration changes of moisture (i.e., moisture content) and other chemical compounds in porous building materials. The technique provides direct measurements of moisture content changes through analysis with a composite model consisting of a dry porous material and a thickness of water equivalent to the moisture content of the material. The current formulation of this composite model relies on certain assumptions, including a monochromatic X-ray photon beam source (i.e., X-ray photons of a single, consistent energy) and that interactions between the X-ray photons and the materials (water and porous material) are independent. However, X-ray sources typically used by researchers in this field of study produce X-ray photon beams over a spectrum of energy levels, or polychromatic X-ray photons. Implications of this inconsistency are introduced and discussed. This paper presents both an overview of fundamental descriptions of the X-ray attenuation measurement technique and results from a parametric experimental study of various porous construction materials, including calcium silicate board, aerated autoclaved concrete, clay brick, cementitious materials, and wood. Results from the parametric investigation indicate the attenuation coefficient of water is dependent on the type and thickness of the porous material.
\end{abstract}

Keywords: Moisture content, X-ray, Attenuation coefficient, Porous media

\section{Introduction}

Moisture, and more specifically varying moisture conditions, often significantly affects structural performance and durability of construction materials. For example, moisture movements may affect warping of timber studs [1], workability [2] and plastic cracking [3] of fresh cementitious materials, maturation of bond strength of lime mortars [4], aging of bitumen binders [5], freeze-thaw damage of concretes [6], etc. Furthermore, moisture influences various chemical, biological and thermal characteristics of materials. In general, moisture and moisture movements are key determining factors in the durability of structures constructed from a multitude of materials. Therefore, experimental approaches for accurate non-destructive monitoring of moisture conditions are essential. Various nondestructive methods are available [7]; however, X-ray

\footnotetext{
* Corresponding author Pease)

Email address: bradley p pease@primekss . com (Brad J.
}

Postprint, Construction and Building Materials attenuation measurements are emerging as a popular technique for monitoring moisture movements in various porous materials, particularly in cracked materials [8-21]. Measurement speed and resolution, ease of twodimensional (or three-dimensional [22]) imaging, availability of facilities, and direct measurement of changes in moisture content are key advantages.

$\mathrm{X}$-ray technologies are commonplace in the medical and security fields; however, application of X-ray attenuation measurements for monitoring of moisture movements in porous media is relatively complex. Changes in moisture content necessitate comparison of multiple $\mathrm{X}$-ray measurements captured at different states (i.e., times). Currently, descriptions of basic and fundamental controlling mechanisms and influential factors are somewhat lacking.

Quantification of moisture content in porous materials from X-ray attenuation measurements is achieved by decomposing a water-containing (saturated or partially saturated) porous material into a dry porous material of the same thickness and a water layer with a thickness

July 9, 2012 
equivalent to the moisture content $[14,16-18,20]$. Using the composite system, equations have been derived allowing for calculation of moisture content changes from X-ray measurements taken at different states. The derived expressions however depend upon certain assumptions. Firstly, calculations assume the incoming Xray photons are of a single, constant energy. Secondly, the quantification of moisture content in porous material with X-ray attenuation is based on a non-interacting composite concept where the attenuation of X-ray photons provided by the porous material and the water are assumed independent. This paper demonstrates these assumptions are not generally valid, and that the interaction between material and water needs to be accounted for to accurately quantify moisture contents in porous materials via X-ray attenuation. Further, the common use of polychromatic X-ray sources, which produce Xray photons over a spectrum of energies, needs to be accounted for to accurately quantify moisture contents in porous materials via X-ray attenuation.

The first section of the paper summarizes the physics of X-ray attenuation, including both monochromatic and polychromatic X-ray photon beams. Key terminology and common misconceptions within the civil/materials engineering communities, particularly the various definitions of attenuation coefficient, are introduced. In the remaining section the composite concept typically utilized to relate changes in X-ray photon counts to changes in moisture content is challenged. Factors affecting the composite concept, including primarily beam hardening and the resulting dependence of the attenuation coefficient of water on the 'parent' material, are discussed. While specific results presented are dependent on the type of materials investigated (calcium silicate board, aerated autoclaved concrete, clay brick, cementitious materials, and wood here) and also likely on the X-ray system used, vital conclusions on and potential pitfalls of the general measurement technique are discussed in this paper.

\section{Fundamentals of the $X$-ray attenuation measure- ment technique}

Fig. 1(a) illustrates the required equipment and the behaviour of an X-ray photon beam during X-ray attenuation measurements. For such measurements a specimen is placed between an X-ray source, which produces a conical beam of X-ray photons, and an X-ray detector (camera used here). Additional details on the interactions between $\mathrm{X}$-ray photons and the specimen are described in a following section. Fig. 1(b) illustrates the commonly accepted composite concept, con- sisting of a dry or partially saturated specimen and a thickness of water, to describe the effect moisture content changes have on X-ray attenuation measurements [8, 14, 16-18, 20, 23]. Using this composite system along with several assumptions, a relationship can be derived to convert changes in X-ray photon counts to changing moisture content of porous materials. One key assumption in the derivation of this relationship is that the porous material does not impact the X-ray attenuation provided by water, and vice versa; therefore, the model illustrated in Fig. 1(b) is referred to as a 'noninteracting' composite concept. The following sections describe the X-ray attenuation measurement technique in detail, provide the derivation of the photon countmoisture content relationship, and introduce other common assumptions.

\subsection{Interactions between $X$-ray photons and building materials}

As illustrated in Fig. 1(a) an X-ray photon beam with an initial intensity, $I_{0}$ is produced by an X-ray source and passes through a specimen. A portion of the photons interact with the specimen, reducing the initial intensity to the transmitted intensity, $I$. The reduction in intensity for a monochromatic X-ray photon beam (i.e., photons of single and constant energy) is described by Eq. 1 and 2:

$\frac{\mathrm{d} I(x)}{\mathrm{d} x}=-\mu \cdot I(x)$

or in the more common form, known as the BeerLambert law [24]:

$I=I_{0} \cdot e^{-\mu \cdot t}$

where $\mu$ is the linear attenuation coefficient $\left[\mathrm{m}^{-1}\right], I(x)$ is the number of $\mathrm{X}$-ray photons present at depth $x$, and $t$ is the thickness of the specimen [m]. The units for intensity are counts or hits, simply indicating the number of X-ray photons.

The linear attenuation coefficient, $\mu$ is equivalent to the total probability of X-ray photon-material interaction per unit length of a material. An X-ray photon passing through a building material may interact on the atomic level in one of three ways - photoelectric effect, Compton scatter, or pair production [25]. Eq. 3 defines $\mu$ therefore as:

$$
\begin{array}{r}
\mu\left(E, Z_{e f f}, \rho\right)=\tau\left(E, Z_{e f f}, \rho\right)+\sigma(\rho)+ \\
\kappa(E \geq 1022 \mathrm{keV}, \ldots)
\end{array}
$$

where $\tau, \sigma$, and $\kappa$ are the photoelectric, Compton, and pair production cross-sections $\left[\mathrm{m}^{-1}\right]$, respectively, all of 


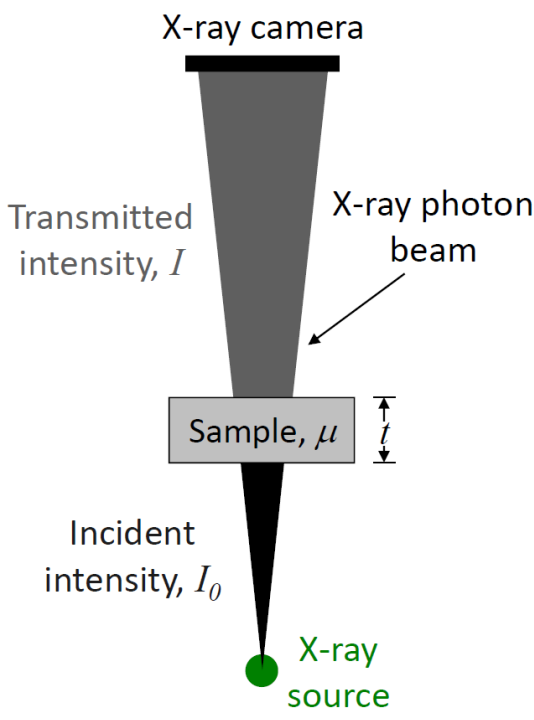

(a)

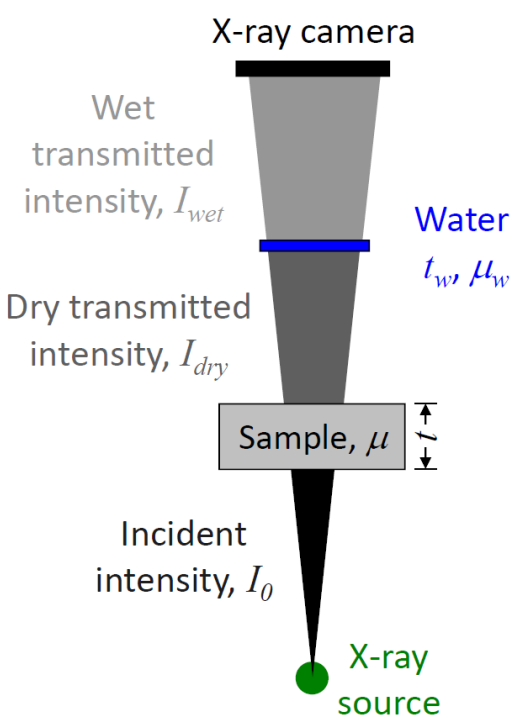

(b)

Figure 1: Schematic representation of a typical X-ray attenuation experimental setup. (a) illustrates the Beer-Lambert Law while (b) illustrates a composite experimental system consisting of a dry specimen and an amount of liquid water to represent movement of moisture.

which are characteristics of the material through which $\mathrm{X}$-ray photons are passing.

The photoelectric effect describes one possible interaction between a photon and a bound atomic electron in the specimen, wherein the photon is absorbed and a photoelectron is produced. The probability of this interaction $(\tau)$ increases with the effective atomic number, $Z_{\text {eff }}$ and density, $\rho\left[\mathrm{kg} / \mathrm{m}^{3}\right]$ of the specimen and decreases significantly with increased $X$-ray photon energy, $E[\mathrm{keV}]$. Compton scatter occurs when an X-ray photon collides with a free electron, causing a change in direction and reduction in energy of the photon. The probability of this interaction $(\sigma)$ increases with $\rho$ and is slightly influenced by $E$ at energies far higher than typically used for the type of investigations discussed here [25]. Pair production, wherein the photon and an atomic nucleus interact to create an electron-positron, only occurs for $E>1022 \mathrm{keV}$ (i.e., minimum kinetic energy required to initiate pair production) [25]. Such energies far exceed typically used X-ray source energy settings [8-23]. Therefore, for $E<200 \mathrm{keV}$ the energy, effective atomic number-, and density-dependent linear attenuation coefficient, $\mu$ can be described according to Eq. 4 [26-28]:

$\mu\left(E, Z_{e f f}, \rho\right)=\left(a \frac{Z_{e f f}^{3.8}}{E^{b}}+c\right) \cdot \rho$

where $a$ and $c$ are coefficients describing the photoelectric and Compton cross-sections, respectively and $b$ describes the shape of the photoelectric cross-section curve. The first term of Eq. 4 is equivalent to the photoelectric cross-section, $\tau$ in Eq. 3, while the second term is equivalent to Compton cross-section, $\sigma$. The Compton cross-section is assumed to be photon energyindependent below $200 \mathrm{keV}$ [26-28].

Fig. 2 shows fitting results of Eq. 4 against tabulated data on linear attenuation coefficients for liquid water, $\mu_{w}$, in [29]. Due to the photoelectric effect low energy $\mathrm{X}$-ray photons are attenuated more efficiently, a trend inherent in all elements and compounds (see [e.g., 29]). Compton cross-section controls $\mu_{w}$-values for photon energies greater than approximately $26 \mathrm{keV}$.

\subsection{Impact of polychromatic $X$-ray sources}

The X-ray source utilized here (described in [8]) and sources utilized by others [7, 9-22] produce X-ray photons over a spectrum of energies (i.e., polychromatic) limited to the user-defined X-ray energy setting, $E_{m}$ as illustrated in Fig. 3(a). Furthermore, the X-ray camera used here, described below, and similar devices used by others $[7,14,17,18]$ detect only the presence of individual X-ray photons and not the energy of individual photons. The use of these non-energy discretizing Xray cameras with a polychromatic $\mathrm{X}$-ray source requires the introduction of an average attenuation coefficient, $\bar{\mu}$ as discussed below. Further, the polychromatic Xray source leads to so-called beam hardening [30] illustrated in Fig 3(b), which must be considered. 


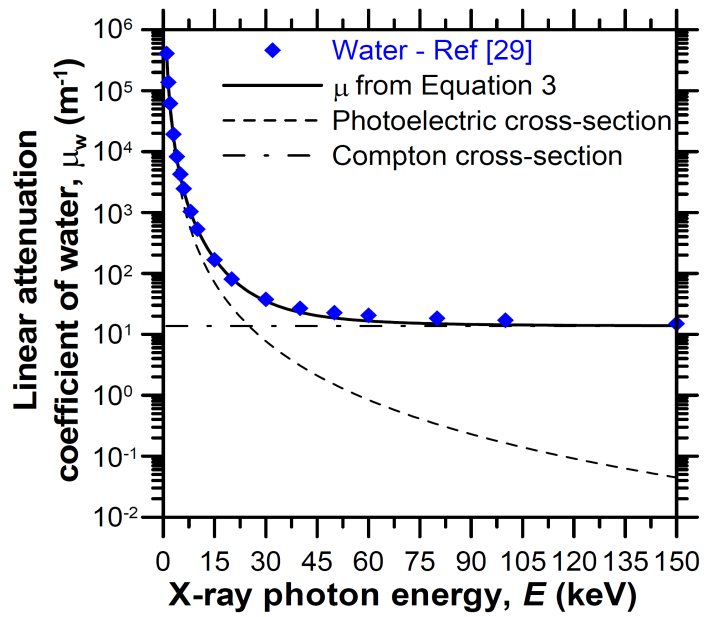

Figure 2: Fitting provided by Eq. 4 to tabulated data on $\mu_{w}$ from [29] including contributions from photoelectric and Compton crosssections $\mathrm{R}^{2}$ was 0.999 for $\mu$ between $0-200 \mathrm{keV}$.

Fig. 3(a) illustrates a possible X-ray spectrum produced by an X-ray source, assuming an X-ray source energy (i.e., $E_{m}$ ) of $85 \mathrm{keV}$. The shape of the initial intensity spectrum presented in Fig. 3(a) comes from [31] where a photon energy detector measured the Xray spectrum produced by the exact source utilized here. The shape of the photon energy spectrum, described by $\Psi_{E}(x)$, changes due to attenuation as it passes through increasing thicknesses, $x$ of material. To illustrate this effect, the transmitted spectrum was calculated by applying Eq. 2 at each X-ray energy level and using the fitted linear attenuation coefficients of water for a 15 mm thickness of water as shown in Fig. 3(b). Attenuation provided by the water progressively increases the average X-ray photon energy, meaning the remaining $\mathrm{X}$-ray photons are 'harder,' hence the term beam hardening. Due to beam hardening, pre-filters, or thicknesses of various materials placed between the X-ray photon source and measurement specimen, are used by some researchers to attenuate the lowest energy X-ray photons prior to their interaction with the measurement specimen. Various materials are used including water in combination with aluminum [30] and gadolinium [8]; however, it should be noted that pre-filters minimize, and do not eliminate, beam hardening [30]. Pre-filters were not utilized in the work presented in this paper.

The X-ray camera used measures only the number of $\mathrm{X}$-ray photons (i.e., intensity) as the sum of the area under the $\Psi_{E}(x)$-curve, as shown in Fig. 3(a) for an initial intensity, $I_{0}$. The X-ray camera used here does not distinguish between photons of varying energies (certain $\mathrm{X}$-ray cameras, capable of measuring the X-ray pho- ton spectra at each pixel [36], could potentially provide vastly more information from X-ray attenuation measurements including monitoring of multi-species concentration changes). Therefore, relating the initial and transmitted intensities, $I_{0}$ and $I$ respectively, shown in Fig. 3(b) is not directly possible using Eq. 1 and 2. Eq. 1 must be modified, removing the linear attenuation coefficient, $\mu$ and introducing an average attenuation coefficient, $\bar{\mu}$ over the spectrum, $\Psi_{E}(x)[32,33]$ defined by:

$\bar{\mu}=\frac{\int_{0}^{E_{m}} \mu\left(E, Z_{e f f}, \rho\right) \cdot \Psi_{E}(x) \mathrm{d} E}{\int_{0}^{E_{m}} \Psi_{E}(x) \mathrm{d} E}$

The X-ray spectrum, $\Psi_{E}(x)$, which can vary depending on X-ray source (see spectra provided in references $[8,12,14,18])$, clearly influences the average attenuation coefficient. Fig. 3(c) shows calculated values of $\bar{\mu}$ as a function of water thickness, where the $\Psi_{E}(x)$ curves were calculated as previously described. The broken line in Fig. 3(c) indicates the value of the linear attenuation coefficient of water $\left(\mu_{w}\right)$ at the X-ray source energy setting of $85 \mathrm{keV}$. The blue diamonds show the average attenuation coefficient for varying thickness of water, as calculated using Eq. 5. The calculations indicate average attenuation coefficients are potentially several orders of magnitude higher than linear attenuation coefficients. The average attenuation coefficient is asymptotic to the linear attenuation coefficient at the maximum X-ray photon energy as a sufficient thickness would attenuate all but the most energetic photons.

Due to beam hardening, $\bar{\mu}$ is no longer a constant, but varies with the location in the material. Fig. 4 illustrates the thickness-dependency of the average attenuation coefficients from measurements on concrete. The specimen thickness-dependency of the average attenuation coefficient can be described by Eq. 6 [32, 33]:

$\bar{\mu}(t)=\frac{\mu_{0}}{(1+\lambda \cdot t)^{2}}=\frac{\bar{\mu}\left(\Psi_{E}(0), Z_{e f f}, \rho\right)}{(1+\lambda \cdot t)^{2}}$

where $\mu_{0}$ is the initial average attenuation coefficient $\left[\mathrm{m}^{-1}\right]$ and $\lambda$ is the beam hardening coefficient of the material $\left[\mathrm{m}^{-1}\right]$. The initial average attenuation coefficient, $\mu_{0}$, may be considered the average attenuation coefficient of an infinitely thin section of material, indicating $\mu_{0}$-values must depend upon the initial $\mathrm{X}$-ray spectrum, $\Psi_{E}(0)$. Further, based on Eq. $4, \mu_{0^{-}}$ values also likely depend on the density $(\rho)$ and effective atomic number $\left(Z_{e f f}\right)$ of the material. Therefore, the second definition for $\bar{\mu}$ is included in Eq. 6. Eqs. 


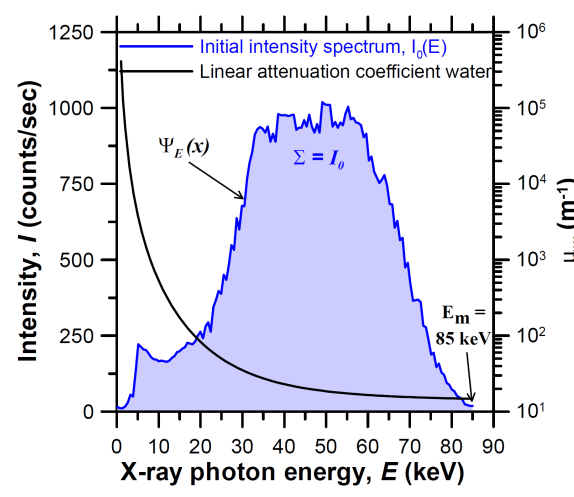

(a)

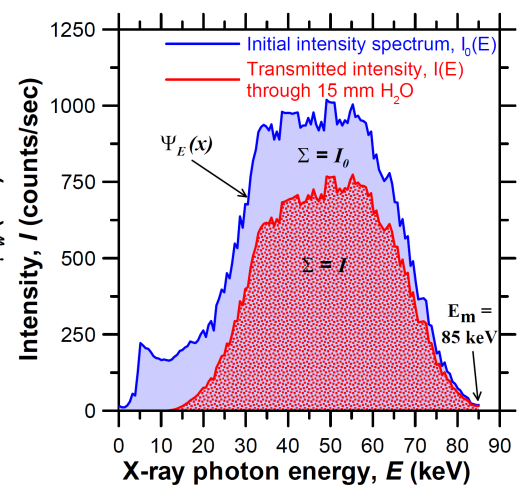

(b)

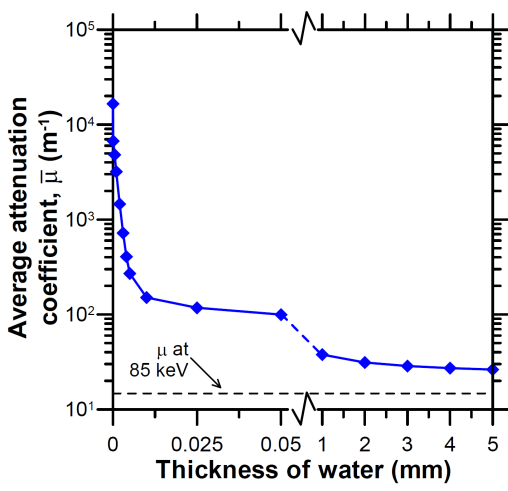

(c)

Figure 3: Illustration of influence of X-ray spectrum on X-ray attenuation measurements including: (a) possible X-ray spectrum produced by X-ray source with an X-ray source energy setting of $85 \mathrm{keV}$ and the photon energy dependent linear attenuation coefficients, (b) calculated transmitted spectrum through a $15 \mathrm{~mm}$ thickness of water, and (c) comparison of average attenuation coefficients at varying thicknesses of water and the linear attenuation coefficient at $85 \mathrm{keV}$.

4 and 5 provide a means to derive an expression for $\bar{\mu}\left(\Psi_{E}(0), Z_{e f f}, \rho\right)$; however, solutions are complicated due to a singularity when the X-ray energy is $0 \mathrm{keV}$. Therefore, Eq. 7 is suggested as a possible means to relate $\mu_{0}$-values to the X-ray source energy setting, $E_{m}$ and material properties, based upon Eq. 4:

$\mu_{0}=\bar{\mu}\left(\Psi_{E}(0), Z_{e f f}, \rho\right)=\left(a^{*} \frac{Z_{e f f}^{3.8}}{E_{m}^{b^{*}}}+c^{*}\right) \cdot \rho$

where the terms $a^{*}, b^{*}$, and $c^{*}$ are analogous to $a, b$, and $c$ described in Eq. 4 for the initial average attenuation coefficient. The term $a^{*} \cdot Z_{e f f}^{3.8}$ can be replaced with a single variable, $\alpha$ to simplify fitting of experimental results presented later due to the complex stoichiometry of the materials tested. Values from Eq. 6 yield tangential slopes of the solid red plot in Fig. 4; therefore, to simplify analysis the effective attenuation coefficient, $\mu_{e f f}$, is utilized.

The effective attenuation coefficient, $\mu_{e f f}\left[\mathrm{~m}^{-1}\right]$, is needed for use in the integrated Beer-Lambert law (Eq. 1) to describe the X-ray attenuation provided by a particular thickness of a material, as defined by Eq. 8:

$$
\begin{aligned}
\mu_{e f f}=\frac{\int_{0}^{t} \bar{\mu} \mathrm{d} x}{t} & =\frac{\int_{0}^{t} \frac{\bar{\mu}\left(\Psi_{E}(0), Z_{e f f}, \rho\right)}{(1+\lambda \cdot t)^{2}} \mathrm{~d} x}{t} \\
& =\frac{\bar{\mu}\left(\Psi_{E}(0), Z_{e f f}, \rho\right)}{1+\lambda \cdot t}
\end{aligned}
$$

Combining Eqs. 8 and 7 provides an expression to describe the effect of X-ray source energy and beam hardening on the effective attenuation coefficients of materials which is measured using a polychromatic X-ray source and an X-ray camera:

$\mu_{e f f}=\frac{\left(\frac{\alpha}{E_{m}^{b^{*}}}+c^{*}\right) \cdot \rho}{1+\lambda \cdot t}$

The various attenuation coefficients illustrated in Fig. 4 are analogous to another material behavior more familiar to the civil engineering community, namely the various measurements of elastic modulus. In this analogy the initial average attenuation coefficient coincides with the initial tangent elastic modulus, the average attenuation coefficient with the tangent elastic modulus, and the effective attenuation coefficient with the secant elastic modulus.

Figs. 3(c) and 4 indicate the potential for error in Xray attenuation measurements if an incorrect attenuation coefficient of water is used. Results from the study presented in the second part of this paper further indicate the attenuation coefficient of water is affected by the type and thickness of the porous specimen.

\subsection{Composite concept for assessment of concentra- tion changes}

Commonly, changes in moisture content (or changes in concentration of other materials [e.g., corrosion products, 23]) in a porous building material are described as the composite system shown in Fig. 1(b). Here an Xray photon beam with initial intensity, $I_{0}$ reduces to a transmitted intensity through a wet material, $I_{w e t}$ in two drops: 1) some photons interact with the dry (or partially saturated) porous material resulting in a dry transmitted intensity, $I_{d r y}$, and 2) additional photons interact with a water layer with thickness $t_{w}$, equivalent to 


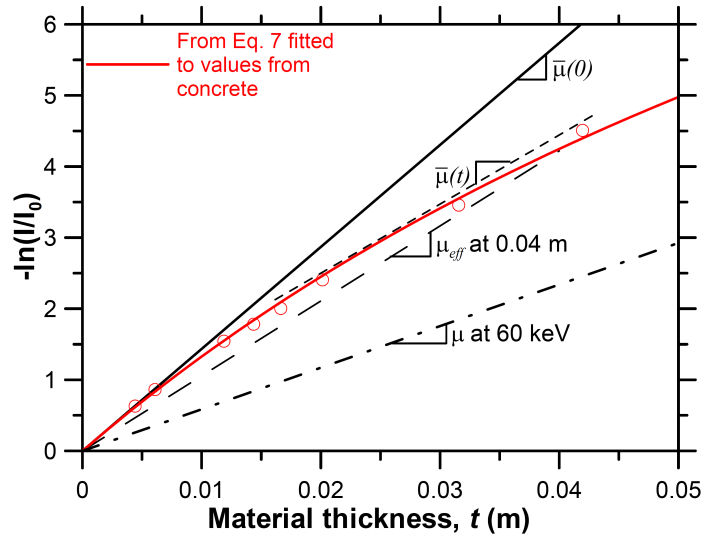

Figure 4: Descriptions of linear, average, and effective attenuation coefficients, $\mu, \bar{\mu}$, and $\mu_{e f f}$, respectively. Values for $\bar{\mu}$ are the tangential slopes of the red line, which is fitted to the shown measured values for concrete (circle symbols) at a maximum X-ray photon energy, $E_{m}$ of $60 \mathrm{keV}$. The linear attenuation coefficient, $\mu$ for concrete at $60 \mathrm{keV}$ found in [29].

the material's water content resulting in a wet transmitted intensity, $I_{w e t}$. The composite system simulates water uptake by increasing the equivalent water thickness, while drying corresponds to a reduction in water thickness. Using Eq. 2 and assuming interactions between $\mathrm{X}$-ray photons and the dry porous material only influence the quantity of photons (and not photon energy), $I_{\text {wet }}$ may be expressed as:

$I_{w e t}=I_{d r y} \cdot e^{-\mu_{w} \cdot t_{w}}=I_{0} \cdot e^{-\mu \cdot t} \cdot e^{-\mu_{w} \cdot t_{w}}=I_{0} \cdot e^{-\mu \cdot t-\mu_{w} \cdot t_{w}}$

for a monochromatic beam, and as derived in [8, 14] moisture content changes can be directly calculated by measurements of $I_{d r y}$ and $I_{w e t}$ according to Eq. 11:

$\Delta w=-\frac{\rho_{w}}{\mu_{w} \cdot t} \ln \left(\frac{I_{w e t}}{I_{d r y}}\right)$

where $\Delta w$ is a change in moisture content $\left[\mathrm{kg} / \mathrm{m}^{3}\right], \rho_{w}$ is the density of water $\left[\mathrm{kg} / \mathrm{m}^{3}\right]$, and $\mu_{w}$ is the linear attenuation coefficient of water. Decreases in moisture content (i.e., drying) can also be directly calculated by Eq. 11 by inverting $\frac{I_{w e t}}{I_{d r y}}$ to $\frac{I_{d r y}}{I_{w e t}}$.

Eq. 11 also provides a measure of the ability to resolve changes in concentration using the X-ray attenuation measurement technique, which is defined as the change in concentration required to attenuate a single X-ray photon. Eq. 12, from [14], describes concentration resolution mathematically.

$R_{\Delta w}=-\frac{\rho_{w}}{\mu_{w} \cdot t} \ln \left(\frac{I_{d r y}-1}{I_{d r y}}\right)$
Eqs. 11 and 12 are central to the quantification of moisture contents in porous materials by X-ray attenuation, and both make use of the attenuation coefficient of water. Typically the non-interactive composite concept is accepted and the effective attenuation coefficient of water is either determined in isolation without interference from the porous material or, in many cases, experimental descriptions do not adequately describe which measure of attenuation coefficient of water is used for calculations of changes in moisture content $[12,14,15,21,22]$. This paper will show the former to be incorrect and indicates the latter requires more attention in future implementations of the X-ray attenuation measurement technique.

\section{Experimental program}

The goal of the experiments presented in this paper was to investigate whether an interaction exists between the attenuation provided by the porous material and the stored water. The effect of type and thickness of the parent material was investigated. Details on the materials tested, the X-ray measurement system, and measurements conducted are provided in the following sections.

\subsection{Materials}

Materials tested included various porous building materials, acrylic, steel, and aluminum. Porous materials included aerated autoclaved concrete, calcium silicate, clay brick, cement paste, concrete, and wood. Specimens with varying thicknesses were created either by stacking individual thin plates of the material (e.g., aluminum, acrylic) or by cutting (e.g., cement paste, clay brick). Aalborg white portland cement was used in cement paste and concrete specimens. The cement paste ( 0.40 water-to-cement ratio) was cured submerged in water for 28 days. Additional details on the concrete used is available in the literature $[16,20]$.

\section{2. $X$-ray facility}

A GNI X-ray system located at the Technical University of Denmark [34], consisting of an X-ray source and camera affixed to three programmable axes, was used for all measurements described here.

The X-ray camera consisted of a $25 \times 25 \mathrm{~mm}^{2}$ cadmium telluride (CdTe) semiconductor detector bump bonded to $252 \times 256$ 16-bit complementary metal-oxide semiconductor (CMOS) pixel circuits [35]. CdTe, a direct conversion X-ray detector, converts X-ray photons to electric signals and is capable of doing so at room 
temperatures. The $64,512(252 \times 256)$ CMOS pixel circuits record the location and number of photons detected over a set period of time, called the integration time (analogous to shutter time in visible-light photography). The number of photons detected during the integration time is the transmitted intensity, $I$ (Eq. 2). CMOS pixel depth (maximum recordable $I$ ) was 65,536 (i.e., $2^{16}$ ); therefore, integration times must be selected to avoid 'overfilling' pixels. The X-ray camera used is described in detail in [35].

Beyond transmitted X-ray photons, the X-ray camera detects background radiation sources, largely in the form of dark current. Other background sources (naturally occurring radioisotopes, cosmic rays, etc.) are minimal due to the materials tested and shielding chamber. Trial measurements of dark current indicated time and temperature variations, therefore, dark current was recorded prior to and subtracted from each X-ray attenuation measurement.

Additional details on the X-ray source [8] and other components of the X-ray equipment in its current configuration are available in the literature [20,23].

\subsection{Determination of attenuation coefficients of mate- rials}

Initial intensity, $I_{0}$ (transmitted intensity through air) was measured with varying X-ray source energies (30, $40,50,60,70,85 \mathrm{keV})$ and currents $(20,30,40,50$, $60,70 \mu \mathrm{A})$. Transmitted intensities, $I$ were measured through varying thicknesses of the porous materials and isolated water using the same X-ray source settings to determine attenuation coefficients. The attenuation coefficient of water was also measured as illustrated in Fig. 1(b) by placing a $20 \mathrm{~mm}$ thickness of water (contained in acrylic containers) in series with specimens of varying material and thickness. All measurements conducted as part of this study were made with a warm-up time of 200 seconds, a stabilization time of 600 seconds, and an integration time of 20 seconds.

\section{Results}

\subsection{Initial intensity of X-ray photon beam}

Fig. 5 shows measured values of average initial X-ray photon intensity per second as measured by the X-ray camera (average of intensities measured by the 64,512 pixels) for varying $\mathrm{X}$-ray source currents and energies. Eq. 13, which relates initial intensity to X-ray source current, $i$ and energy, $E_{m}$, was found to accurately fit

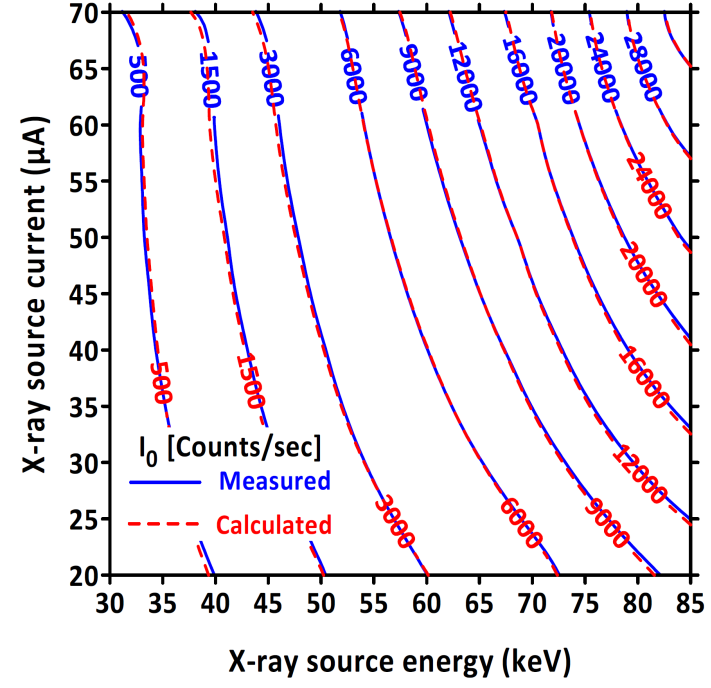

Figure 5: Contour plot of the initial intensity $I_{0}$ as a function of the input X-ray source energy and current. The blue contour lines indicate measured values, while red contours indicate calculated values from Eq. 13.

\begin{tabular}{cc}
\multicolumn{2}{c}{ Table 1: Values of coefficients $C_{1-6}$ in Eq. 13.} \\
\hline Fitting coefficient & Value \\
\hline$C_{1}$ & -0.0187 \\
$C_{2}$ & $1.502 \times 10^{-4}$ \\
$C_{3}$ & -0.0800 \\
$C_{4}$ & 2.0283 \\
$C_{5}$ & 1.0607 \\
$C_{6}$ & 1.00236 \\
\hline
\end{tabular}

measured initial intensity:

$$
\begin{array}{r}
I_{0}=\left(C_{1} \cdot i\right) \cdot\left(C_{2} \cdot E_{m}^{4}+C_{3} \cdot E_{m}^{3}+C_{4} \cdot E_{m}^{2}+\right. \\
\left.C_{5} \cdot E_{m}+C_{6}\right)
\end{array}
$$

where $C_{1-6}$ are fitting parameters shown in Table 1. Eq. 13 is a polynomial fitting of measured results and therefore is only applicable for the investigated $\mathrm{X}$-ray source inputs (i.e., $30 \leq E_{m} \leq 85 \mathrm{keV}$ and $20 \leq i \leq$ $70 \mu \mathrm{A})$. This expression and the values for the coefficients may not be directly transferrable to other X-ray sources; however values for $I_{0}$ are needed to derive $I_{d r y}$ for determination of measurement resolution (i.e., Eq. 12).

\subsection{Effective attenuation coefficients of materials}

Fig. 6 illustrates the typical effects of X-ray source energy and materials thickness on effective attenuation coefficient, $\mu_{e f f}$. Measured values in Fig. 6 are indicated by symbols, while fits provided by Eq. 9 are 


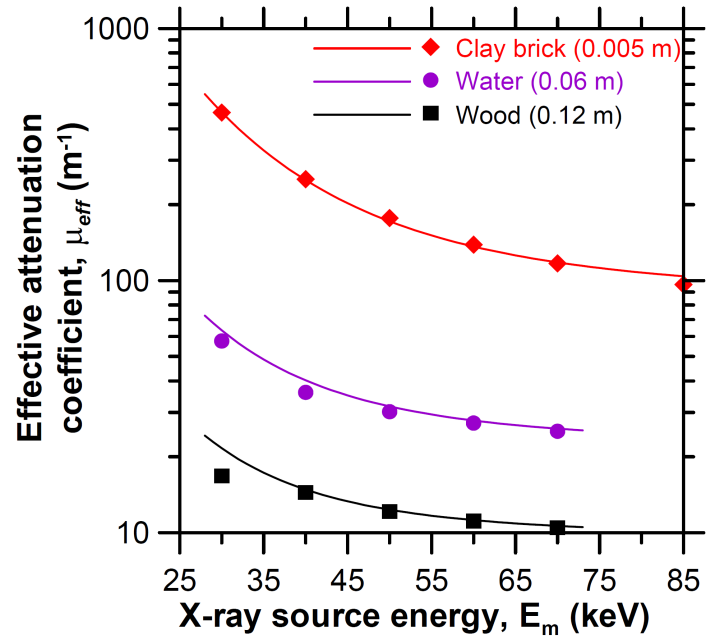

(a)

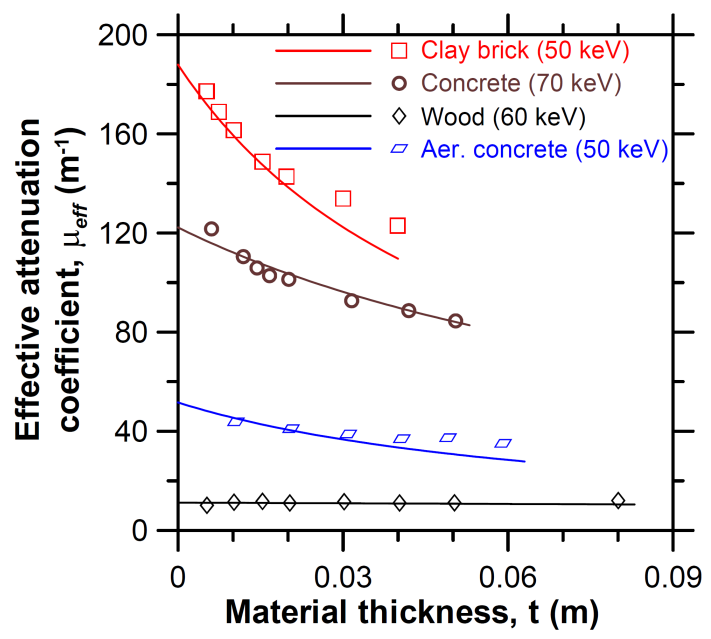

(b)

Figure 6: Influence of (a) X-ray source energy setting, $E_{m}$ and (b) material thickness, $t$ on effective attenuation coefficient. Measured values indicated by symbols, while lines indicate fits provided by Eqs. 7 and 8.

shown as the solid lines. Table 2 provides values for $\alpha$, $b^{*}, c^{*}, \lambda$ along with coefficients of determination $\left(R^{2}\right)$ of the resulting fits. Fig. 6(a) indicates $\mu_{e f f}$-values decrease as X-ray source energy, $E_{m}$ increases, and that the $\mathrm{X}$-ray source energy-effect can be accurately estimated by Eq. 7 proposed in Sect. 2.2. Fig. 6(b) shows $\mu_{e f f^{-}}$ values may be affected by material thickness, depending on the type of material. For example, the thickness of wood has a minimal impact on $\mu_{e f f}$-values, while increased clay brick thickness causes significant reductions in $\mu_{e f f}$-values. Eq. 9, which considers the X-ray source energy-effect described by Eq. 7 and the beam hardening-effect described by Eq. 6, provided a worst case $\mathrm{R}^{2}$-value of 0.861 for acrylic. The lowest $\mathrm{R}^{2}$-value for porous materials was 0.913 for aerated concrete. Alternative expressions to describe the beam hardeningeffect were suggested in [32, 33]; however Eq. 6 was selected due to its inherent physical logic (i.e., beam hardening effect, $1+\lambda \cdot t$ in Eqs. 6 and 9 equals 1 with zero thickness).

Figs. 7(a)-(d), which illustrate both the material thickness, $t$ and X-ray source energy, $E_{m}$ effects on

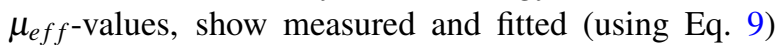
$\mu_{e f f}$-values for water, calcium silicate, clay brick, and aluminum, respectively. Measurement points are indicated by blue symbols with the measured $\mu_{e f f}$-values indicated by the adjacent number. The red isolines show the fitted $\mu_{e f f}$-values provided by Eq. 9 . Fitting parameters are provided for all materials in Table 2 , including water. The impact of hardening coefficient, $\lambda$ is indicated by comparison of Figs. 7(a)-(d) where $\lambda$ increases from $0.888 \mathrm{~m}^{-1}$ in (a) to $8.94 \mathrm{~m}^{-1}$ in (b), 17.8 $\mathrm{m}^{-1}$ in (c) and $57.7 \mathrm{~m}^{-1}$ in (d). As $\lambda$ increases, the effect of specimen thickness on the $\mu_{e f f \text {-isolines be- }}$ comes increasingly more significant - with only minimal changes in $\mu_{e f f}$-values as the thickness of water increases (Fig. 7(a)). For aluminum (Fig. 7(d)), thickness increase drastically reduces $\mu_{\text {eff }}$-values. Fig. 6(b) also illustrates the impact of material type and thickness on $\mu_{e f f}$-values.

\subsection{Coupled effect of parent material on effective at- tenuation coefficient of water}

Fig. 8(a) indicates the influence of water and parent material thickness on measured values of the effective attenuation coefficient of water, $\mu_{e f f, w}$. Calcium silicate in various thicknesses $(0,0.02,0.04$, and $0.08 \mathrm{~m})$ was used as the parent material in this case while water thickness was also varied (approximately 0.01, 0.02, 0.04 , and $0.06 \mathrm{~m}$ ). While the effect of the parent material's thickness is evident, no clear trend was identified concerning the impact of water thickness. Increasing the water thickness from 0.01 to 0.02 appears to result in an increased $\mu_{e f f, w}$-value, followed by a subsequent decrease with increased water thickness. Measurement variability may explain the apparent differences with water thickness. However, Fig. 8(a) clearly shows a coupling effect of the thickness of the calcium silicate on the effective attenuation coefficient of water. Therefore, the term coupled effective attenuation coefficient of water, $\mu_{e f f, w}(t)$; which is a function of the parent material thickness, $t$; is introduced here.

Fig. 8(b) shows this coupling effect of the parent material on the effective attenuation coefficient of water 


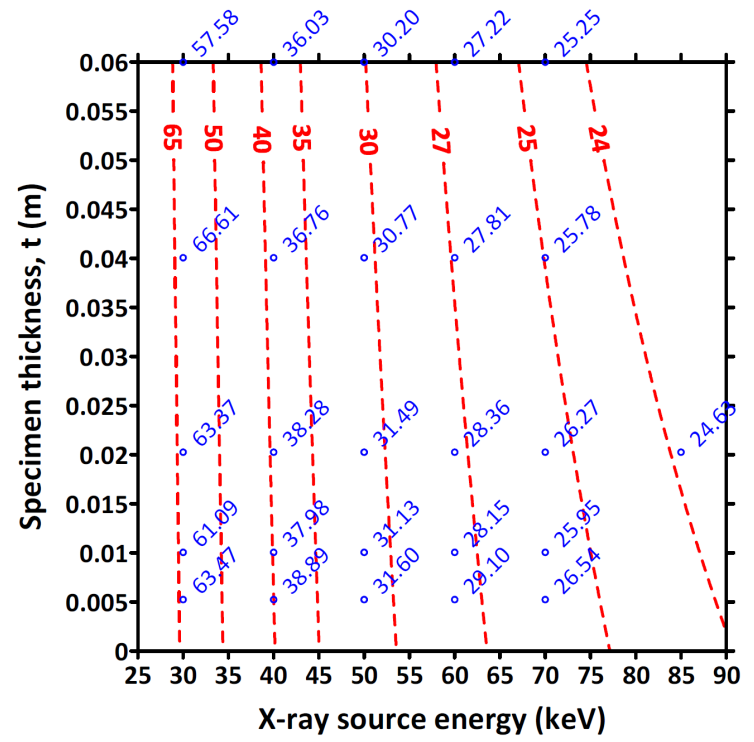

(a)

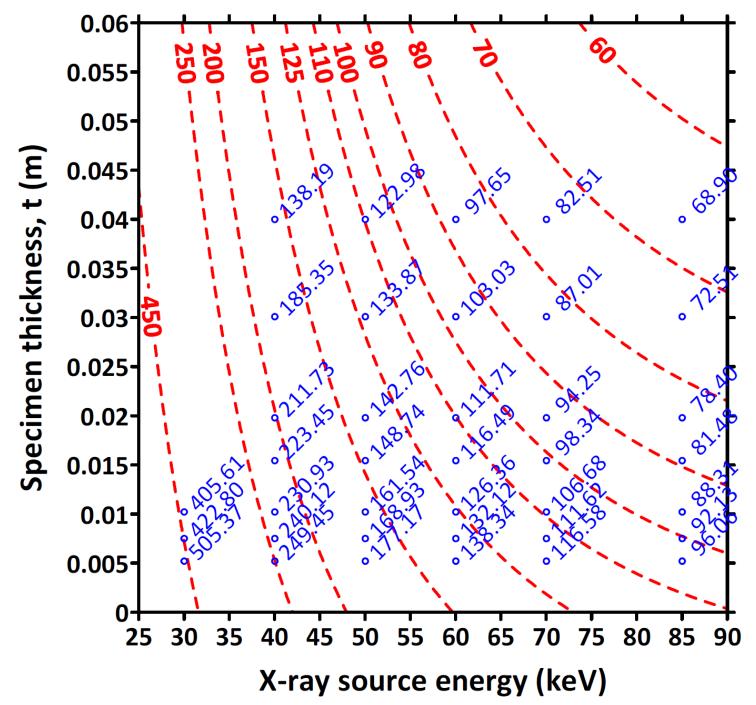

(c)

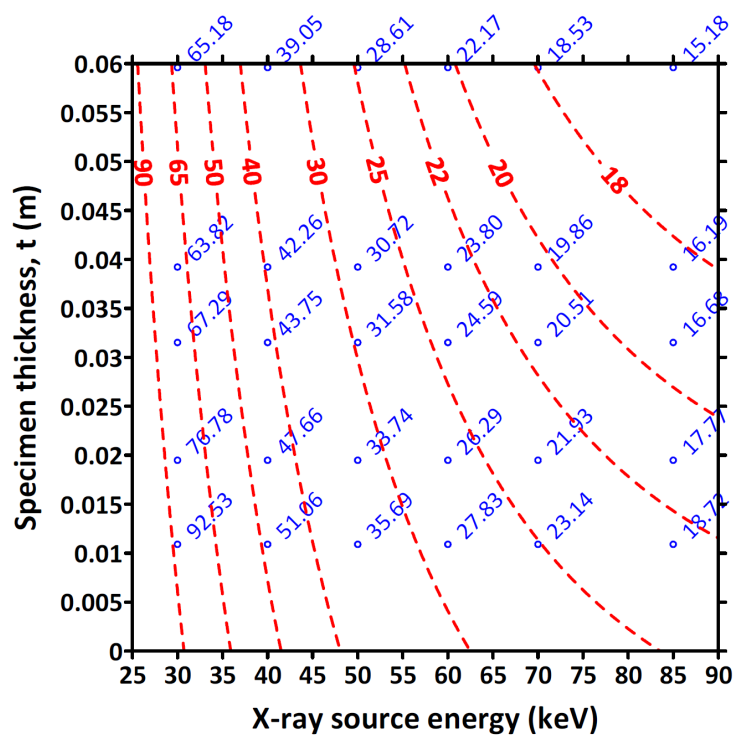

(b)

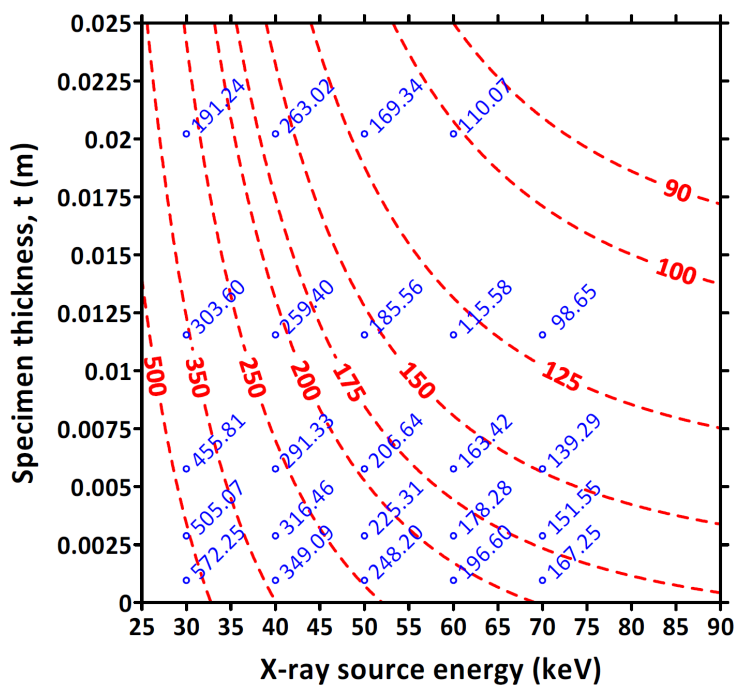

(d)

Figure 7: Comparison of measured and estimated (Eq. 9) effective attenuation coefficients for (a) water, (b) calcium silicate, (c) clay brick, and (d) aluminum as function of specimen thickness and X-ray source energy. Blue data points indicate measured points, while the red broken isolines indicate fitted values from Eq. 9. 
POSTPRINT: Pease BJ, Scheffler GA, Janssen H. 2012. Monitoring moisture movements in building materials using X-ray attenuation: Influence of beam-hardening of polychromatic X-ray photon beams. Construction and Building Materials, 36:419-429.

doi:10.1016/j.conbuildmat.2012.04.126

Table 2: Values for parameters in Eq. 9 for various materials including the coefficient of determination $\left(\mathrm{R}^{2}\right)$ of the fits.

\begin{tabular}{cccccccccc}
\hline \multirow{2}{*}{ Parameter } & \multicolumn{7}{c}{ Materials } \\
\cline { 2 - 10 } & Acrylic & $\begin{array}{c}\text { Aerated } \\
\text { concrete }\end{array}$ & aluminum & $\begin{array}{c}\text { Clay } \\
\text { brick }\end{array}$ & $\begin{array}{c}\text { Calcium } \\
\text { silicate }\end{array}$ & $\begin{array}{c}\text { Cement } \\
\text { paste }\end{array}$ & Concrete & Wood & Water \\
\hline$\rho\left[\mathrm{kg} / \mathrm{m}^{3}\right]$ & 1186 & 422 & 2700 & 1795 & 271 & 1440 & 2200 & 480 & 1000 \\
$\alpha$ & 484.4 & 3999.8 & 3112.8 & 4442.7 & 5228.4 & 6750.4 & 3840.0 & 481.2 & 790.3 \\
$b^{*}$ & & & & & 2.9 & & & & \\
$c^{*}$ & 0.022 & 0.075 & 0.060 & 0.052 & 0.078 & 0.064 & 0.106 & 0.020 & 0.022 \\
$\lambda\left[\mathrm{m}^{-1}\right]$ & 3.97 & 13.6 & 57.7 & 17.8 & 8.94 & 12.4 & 9.00 & 0.863 & 0.888 \\
$\mathrm{R}^{2}$ & 0.861 & 0.913 & 0.948 & 0.990 & 0.976 & 0.991 & 0.953 & 0.999 & 0.987 \\
\hline
\end{tabular}

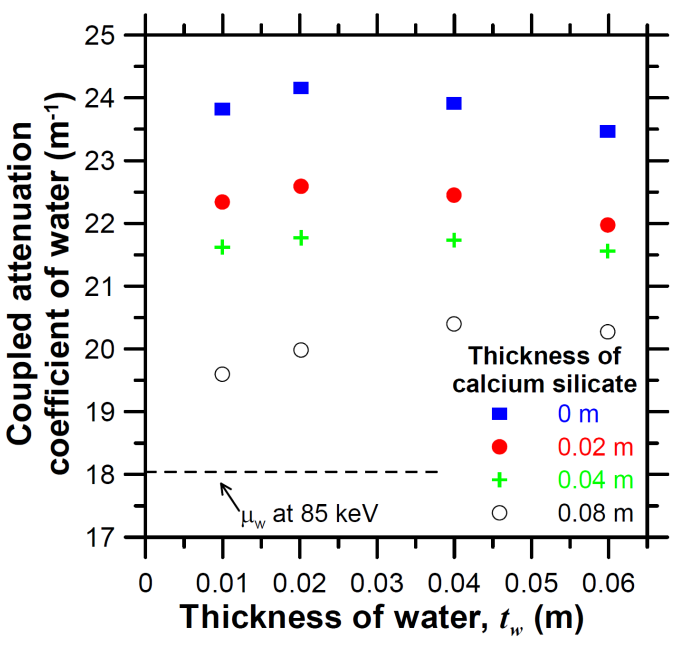

(a)

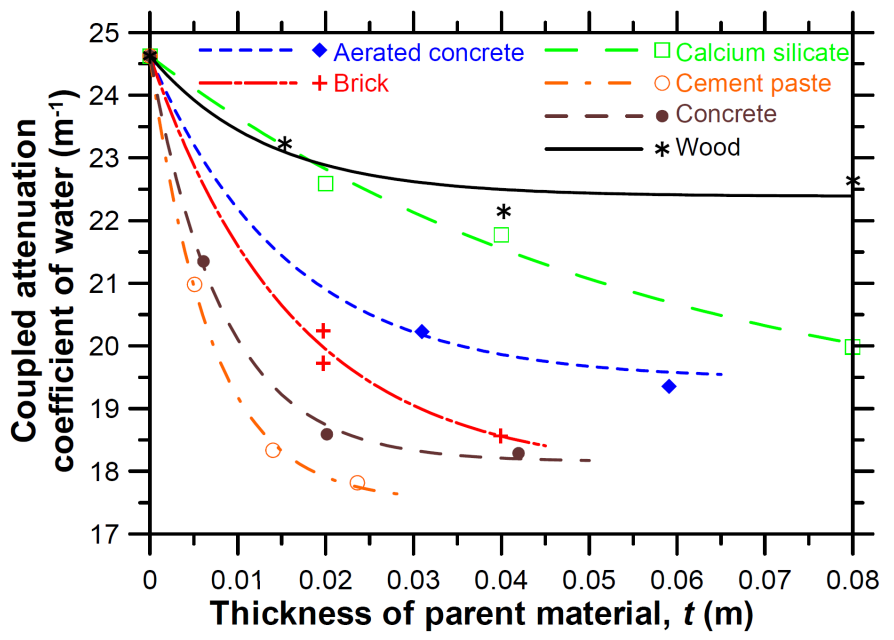

(b)

Figure 8: (a) Influence of water thickness on measured coupled attenuation coefficient of water with an X-ray source energy of $85 \mathrm{keV}$ measured through calcium silicate parent specimen with varying thickness and (b) coupled attenuation coefficient of water with an X-ray source energy of 85 $\mathrm{keV}$ with varying types and thicknesses of parent materials with symbols indicating measured values and lines indicating fits provided by Eq. 14 . 
occurs for all porous materials tested. The symbols in Fig. 8(b) indicate measured effective attenuation coefficients of water when the X-ray photon beam passed through varying thickness of the various parent materials prior to interacting with the water. As shown in the figure, the measured effective attenuation coefficient of water decreases from an average of $24.6 \mathrm{~m}^{-1}$ for a $0 \mathrm{~mm}$ thickness of parent material to as low as $17.8 \mathrm{~m}^{-1}$ for a $23.6 \mathrm{~mm}$ thickness of cement paste. It should be noted that values of $\mu_{e f f, w}(t)$ presented in Fig. 8(b) were measured using a constant $0.02 \mathrm{~m}$ thickness of water as Fig. 8 (a) indicates water thickness is of less importance. The exponential decay model described in Eq. 14 was found to accurately fit measurements:

$$
\begin{array}{r}
\mu_{e f f, w}(t)=\mu_{e f f, w}(\infty)+\left[\mu_{e f f, w}(0)-\right. \\
\left.\mu_{e f f, w}(\infty)\right] \cdot e^{-\eta \cdot t}
\end{array}
$$

where, $\mu_{e f f, w}(\infty)$ is the coupled effective attenuation coefficient of water through an infinite thickness of the parent material $\left[\mathrm{m}^{-1}\right], \mu_{e f f, w}(0)$ is the coupled effective attenuation coefficient through a zero thickness of the parent material $\left[\mathrm{m}^{-1}\right]$, and $\eta$ is the parent material's coupling effect $\left[\mathrm{m}^{-1}\right]$. The lines in Fig. 8(b) indicate the fits provided by Eq. 14 for the various parent materials. Table 3 lists the fitted values for coefficients and the coefficients of determination for the fits provided by Eq. 14.

\section{Discussion}

Comparison of results in Fig. 8(b) showing the coupling effect of the various porous materials and values for the hardening coefficient, $\lambda$ of the porous materials presented in Table 2 indicates a potential relationship. Fig. 9 assesses this relationship, where the coupling effect is defined in accordance with Eq. 14 as $\ln \left[\mu_{e f f, w}(0)-\mu_{e f f, w}(\infty)\right] \cdot \eta$. Fig. 9 indicates the coupling effect tends to increase with the hardening coefficient of the porous material. Further investigations are required to verify and quantify this relationship. However, Fig. 9 and a comparison of results in Fig. 8(b) and Table 2 indicate a strong correlation between beam hardening and the reduction in the coupled effective attenuation coefficient of water.

Results presented in Fig. 8(b) necessitated the introduction a fourth attenuation coefficient of water, coupled effective $\left(\mu_{e f f, w}(t)\right)$, to describe the attenuation behaviour of water in composite systems. The lack of sufficient descriptions of fundamental mechanisms and the apparently previously undiscovered coupled effect has lead in many cases to unintentionally vague

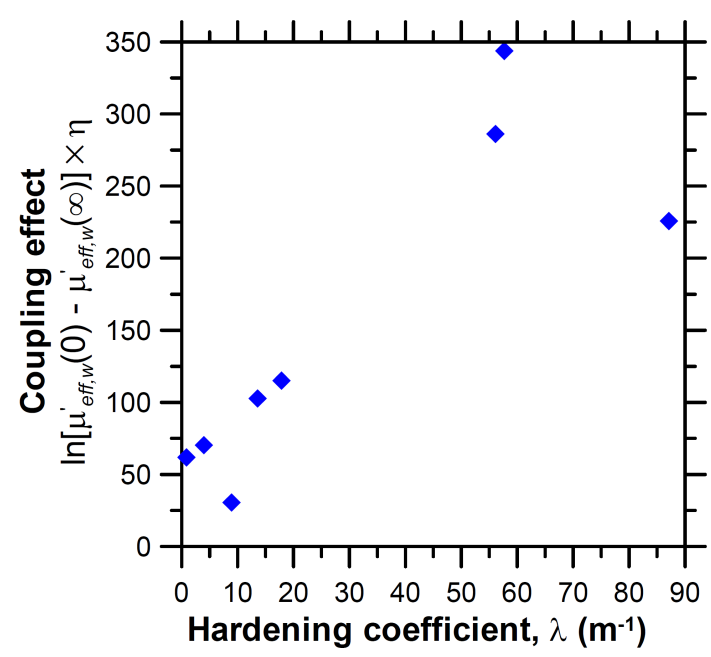

Figure 9: Hardening coefficient, $\lambda$ of the parent materials versus the coupling effect of the parent material on the coupled effective attenuation coefficient of water.

descriptions of experimental procedures and potential for mistakes when performing X-ray attenuation measurements with polychromatic X-ray sources. Specifically, a review of the literature yields little information on which attenuation coefficient of water was used for determination of moisture contents in many published results, and in some cases incorrect values being used. In $[14,15,21,22]$, the experimental procedure descriptions do not specify how or if an attenuation coefficient was measured or if tabulated (i.e., linear) values were simply used. Others $[8,12,18]$ have correctly indicated the effective attenuation coefficient of water should be measured and used, but do not indicate if they accounted for the coupled effect of the parent material. Eq. 15, a modification of Eq. 11, therefore describes an improved calculation for concentration changes using a polychromatic X-ray photon source:

$\Delta w=-\frac{\rho_{w}}{\mu_{e f f, w}(t) \cdot t} \ln \left(\frac{I_{w e t}}{I_{d r y}}\right)$

where $\mu_{e f f, w}(t)$ is the parent material thicknessdependent (coupled) effective attenuation coefficient of water. The coupled effective attenuation coefficient of the water therefore must be directly measured for individual investigations, and tabulated values for $\mu_{w}$ must be avoided. The following procedure describes one method for determining values of $\mu_{e f f, w}(t)$ when using a polychromatic X-ray photon source:

1. Measure the transmitted intensity through a conditioned (partially saturated or dried) specimen with given material type and thickness and an 
Table 3: Values for parameters in Eq. 14 for various materials including the coefficient of determination $\left(\mathrm{R}^{2}\right)$ of the fits

\begin{tabular}{ccccccccc}
\hline & \multicolumn{7}{c}{ Materials } \\
\cline { 2 - 9 } Parameter & Acrylic & $\begin{array}{c}\text { Aerated } \\
\text { concrete }\end{array}$ & aluminum & $\begin{array}{c}\text { Clay } \\
\text { brick }\end{array}$ & $\begin{array}{c}\text { Calcium } \\
\text { silicate }\end{array}$ & $\begin{array}{c}\text { Cement } \\
\text { paste }\end{array}$ & Concrete & Wood \\
\hline$\mu_{\text {eff,w }}(\infty)$ & 21.6 & 19.5 & 18.5 & 18.0 & 18.6 & 17.5 & 118.2 & 22.4 \\
$\mu_{e f f, w}(0)$ & & \multicolumn{7}{c}{24.63} \\
$\eta$ & 62.9 & 64.0 & 185.2 & 60.7 & 17.7 & 145.3 & 120.1 & 75.1 \\
$\mathrm{R}^{2}$ & 0.989 & 0.975 & 0.995 & 0.995 & 0.991 & 0.999 & 0.999 & 0.943 \\
\hline
\end{tabular}

empty thin-walled acrylic (or similar) container with known inner dimensions at user-defined Xray source setting(s), or $I_{e}$. Either a single wedgeshaped container or a series of parallel-walled containers with varying water thickness may be used for this purpose (or a combination of both). The maximum water thickness, $t_{w}$ should, in either case, be similar to the anticipated maximum change in moisture content of porous material. Wedge-shaped containers provide $\mu_{e f f, w}(t)$-value determinations with a single measurement. However, as the water thickness varies along the height, careful alignment is required and only 252 measurement locations (number of pixels in a row) are averaged for each thickness. A series of parallelwalled containers requires multiple measurements, but provides $64,512(252 \times 256)$ measurements for a single water thickness. Parallel-walled containers were used here.

2. Fill the acrylic container with water or other material investigated [e.g., corrosion products, 23] and again measure the transmitted intensity through the conditioned specimen, acrylic, and water at the same X-ray source setting(s), $I_{f}$.

3. Calculate the coupled effective attenuation coefficient of water as the quotient of $-\ln \left(\frac{I_{f}}{I_{e}}\right)$ over the water thickness, $t_{w}$.

Alternatively, values for $I_{e}$ and $I_{f}$ determined by measuring the transmitted intensity through a dry and saturated specimen, respectively, would likely yield the same value for $\mu_{e f f, w}(t)$.

Fig. 10 illustrates the impact of using various attenuation coefficients when computing changes in moisture contents. In this example, a 0.40 water-to-cement ratio cement paste specimen (28 days curing submerged in $20^{\circ} \mathrm{C}$ water) was dried through solvent exchange and subsequently exposed to liquid water from the specimen's top surface. Transmitted intensities were recorded from the dried specimen and repeatedly after exposure to water. The moisture profiles shown were recorded at the same time (after 8 days of exposure to

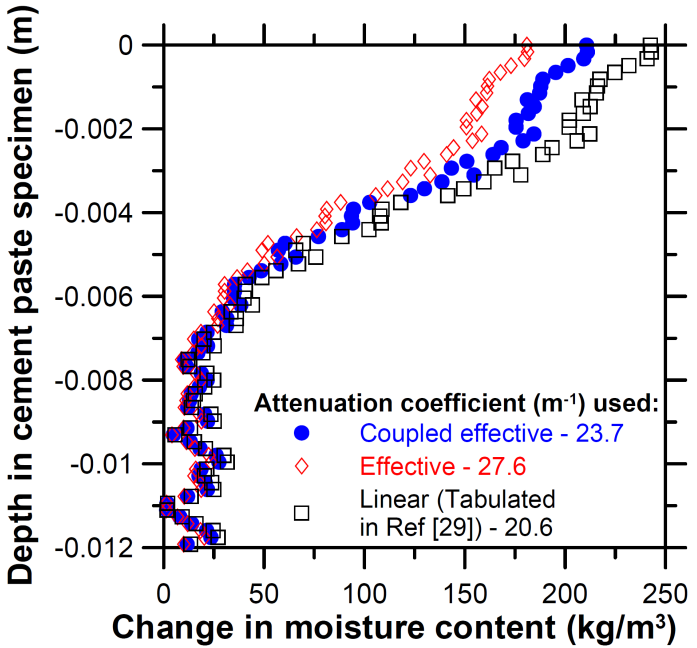

Figure 10: Example of impact of using different attenuation coefficients of water on measured change in moisture content. Data presented was collected after 8 days of exposure of liquid water to the surface of a dried (through solvent exchange) cement paste specimen using an X-ray source energy of $60 \mathrm{keV}$.

water), but moisture contents were computed using different attenuation coefficients for water. Attenuation coefficients for water included a tabulated (in [29]) value for the linear attenuation coefficient of water at $60 \mathrm{keV}$, $20.6 \mathrm{~m}^{-1}$; the effective attenuation coefficient of water at $60 \mathrm{keV}, 27.6 \mathrm{~m}^{-1}$ (according to Eq. 9 and the fitting parameters presented in Table 2); and the coupled effective attenuation coefficient, measured to be $23.7 \mathrm{~m}^{-1}$. Differences in moisture content (from correct values calculated using the coupled effective attenuation coefficient) as large as $31.8 \mathrm{~kg} / \mathrm{m}^{3}$ were found in this case.

Eqs. 11 and 15 indicate differences in the calculated moisture content are inversely proportional to the various attenuation coefficients. Table 4 provides an overview of the percentage difference that would result from using incorrect attenuation coefficients of water assuming the X-ray source energy is $85 \mathrm{keV}$, the parent specimen thickness is $0.02 \mathrm{~m}$, and a water thickness 
POSTPRINT: Pease BJ, Scheffler GA, Janssen H. 2012. Monitoring moisture movements in building materials using X-ray attenuation: Influence of beam-hardening of polychromatic X-ray photon beams. Construction and Building Materials, 36:419-429.

Table 4: Values for various attenuation coefficients of water in series with various parent materials and the potential error (\%) in calculations of moisture content from X-ray attenuation measurements if the linear, $\mu_{w}$ or effective, $\mu_{e f f, w}$ attenuation coefficient was used rather than the coupled effective attenuation coefficient, $\mu_{e f f, w}(t)$

\begin{tabular}{ccccccc}
\hline Parent Material & $\begin{array}{c}\text { Aerated } \\
\text { concrete }\end{array}$ & $\begin{array}{c}\text { Clay } \\
\text { brick }\end{array}$ & $\begin{array}{c}\text { Calcium } \\
\text { silicate }\end{array}$ & $\begin{array}{c}\text { Cement } \\
\text { paste }\end{array}$ & Concrete & Wood \\
\hline$\mu_{w}\left[\mathrm{~m}^{-1}\right]$ & & \multicolumn{6}{c}{18.04} \\
$\mu_{e f f, w}\left[\mathrm{~m}^{-1}\right]$ & & \multicolumn{2}{c}{24.13} \\
$\mu_{e f f, w}(t)\left[\mathrm{m}^{-1}\right]$ & 20.9 & 20.0 & 22.8 & 17.9 & 18.7 & 22.9 \\
\hline \hline Error using $\mu_{w}(\%)$ & $\mathbf{1 5 . 8}$ & $\mathbf{1 0 . 6}$ & $\mathbf{2 6 . 5}$ & $\mathbf{0 . 7}$ & $\mathbf{3 . 9}$ & $\mathbf{2 6 . 9}$ \\
Error using $\mu_{e f f, w}(\%)$ & $\mathbf{1 3 . 5}$ & $\mathbf{1 7 . 4}$ & $\mathbf{5 . 5}$ & $\mathbf{2 5 . 8}$ & $\mathbf{2 2 . 4}$ & $\mathbf{5 . 2}$ \\
\hline
\end{tabular}

of $0.01 \mathrm{~m}$ was used to determine the effective attenuation coefficient of water. For the materials investigated and with the stated assumptions, incorrect use of either the linear or effective attenuation coefficient for water would result in calculation errors of up to $26.9 \%$. Table 4 clearly indicates that even the use of the effective attenuation coefficient of water, $\mu_{e f f, w}$, measured without the parent material results in potentially excessive errors. Further, these results indicate verification of X-ray attenuation measured moisture content changes should be completed in future works using a comparative experimental technique. For example, gravimetric determination of moisture content changes from two 'known' conditions (e.g., moisture content change from a partially saturated to vacuum saturated conditions) could be compared to identical X-ray attenuation measurements. Such comparative experiments, while only reliably verifying a single moisture content change, would provide additional indications of the validity of the X-ray attenuation measurement technique and the importance of using the correct attenuation coefficient of water.

Eq. 16, a modification of Eq. 12, describes the concentration resolution when using the coupled effective attenuation coefficient of water.

$R_{\Delta w}=-\frac{\rho_{w}}{\mu_{e f f, w}(t) \cdot t} \ln \left(\frac{I_{d r y}-1}{I_{d r y}}\right)$

As shown in Fig. 8, the thickness of the water, $t_{w}$ used for determination of $\mu_{e f f, w}(t)$-values appears to have a minimal impact. However, the water thickness should likely closely resemble the expected maximum change in moisture content of the parent material. In this way the determination of $\mu_{e f f, w}(t)$ will also act as a check to ensure the X-ray source settings and specimen thickness selected will be able to detect anticipated changes in moisture content.

Using the results presented above, the measurement resolution can be calculated using Eq. 16. Values for $I_{d r y}$ are computed using Eq. 1 , where $I_{0}$ is determined from Eq. 13 and values for $\mu_{e f f}$ of the various porous

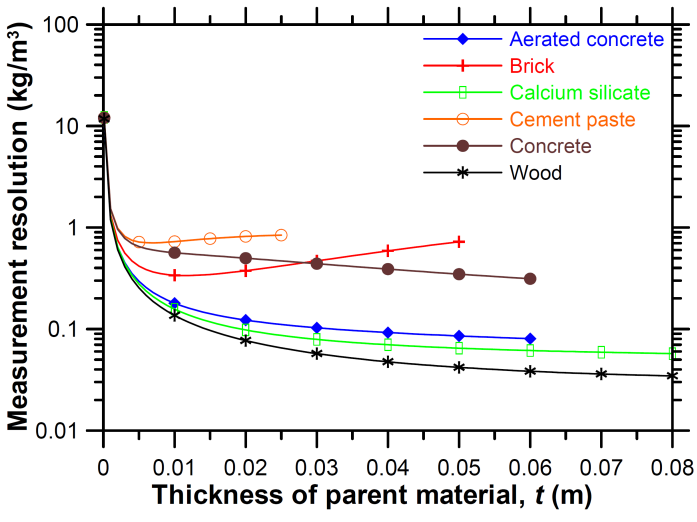

Figure 11: Resolution of moisture content changes for various materials and thicknesses with an X-ray source energy of $85 \mathrm{keV}$ and current of $70 \mu \mathrm{A}$ using fitted effective attenuation coefficients of the various building materials using Eq. 9 and coupled effective attenuation coefficient of water using Eq. 15.

materials determined using Eq. 9 and the regression coefficients in Table 2. Fig. 11 shows the concentration resolutions possible for the various parent materials using an X-ray source energy of $85 \mathrm{keV}$ and current of 70 $\mu \mathrm{A}$. The curves consider the beam hardening caused by the parent materials and the coupling effect on the effective attenuation coefficients of water, which occurs when polychromatic X-ray sources are used. For cement paste and clay brick optimal thicknesses are discovered, whereas for the other materials increasing the specimen thickness continues to improve measurement resolution for the studied conditions.

\section{Summary and conclusions}

This paper presents a detailed description of the controlling mechanism behind X-ray attenuation measurement using both monochromatic and polychromatic Xray sources and non-energy discretizing X-ray cameras. Differences in measurements taken with monochromatic and polychromatic sources are described. Vari- 
ous attenuation coefficients, including linear, average, effective, and coupled effective (for water only), were defined and described in order to shed light on possible mistakes made in previous investigations. It is concluded that using tabulated values of the linear attenuation coefficient, $\mu_{w}$ of water should not be used for calculating moisture content changes.

Additionally, a parametric investigation on material type, thickness and X-ray source energy settings on the ability to resolve changes in moisture content was presented. Results obtained through the parametric studies performed on aluminum, acrylic, clay brick, aerated autoclaved concrete, cement paste, concrete, calcium silicate, and wood indicated that:

- The effective attenuation coefficient of water is affected by the type and thickness of the parent specimen, necessitating the introduction of the coupled effective attenuation coefficient of water, $\mu_{e f f, w}(t)$. Therefore, when utilizing the X-ray attenuation measurement technique to calculate moisture content (or other material concentration) changes, the attenuation coefficient of water must be directly measured while the parent specimen is in place. A procedure for determining $\mu_{e f f, w}(t)$ is presented.

- It was found that calculations of change in moisture content (i.e., Eq. 15) may vary by up to $26.9 \%$ if the incorrect attenuation coefficient of water is used.

- Material-dependent optimization functions - in terms of ability to resolve water - have been developed for clay brick, aerated autoclaved concrete, cement paste, concrete, calcium silicate, and wood. These functions consider specimen thickness, X-ray source energy and current, beam hardening caused by the parent material, and the coupled effective attenuation coefficient of water. This extensive study provides a simple means for determination of proper specimen size and X-ray energy settings for a variety of materials.

\section{Acknowledgements}

The financial support of the Danish Expert Centre for Infrastructure Constructions, the Hans-Christian-Ørsted fund, and the funding by the Danish research council (project number 274-07-0393) is gratefully acknowledged.

\section{References}

[1] M. Bäckström, M. Al-Emrani, R. Kliger, Timber-framed partition walls and their restraining effect on warp in built-in wall studs - models for twist, Construction and Building Materials 23 (12) (2009) $3556-3563$.

[2] R. Hendrickx, S. Roels, K. V. Balen, Measuring the water capacity and transfer properties of fresh mortar, Cement and Concrete Research 40 (12) (2010) 1650 - 1655.

[3] P. Lura, B. Pease, G. Mazzotta, F. Rajabipour, J. Weiss, Influence of shrinkage-reducing admixtures on the development of plastic shrinkage cracks, ACI Materials Journal 104 (2) (2007) 187-194.

[4] A. El-Turki, R. J. Ball, S. Holmes, W. J. Allen, G. C. Allen, Environmental cycling and laboratory testing to evaluate the significance of moisture control for lime mortars, Construction and Building Materials 24 (8) (2010) 1392 - 1397.

[5] L. Poulikakos, M. Partl, Evaluation of moisture susceptibility of porous asphalt concrete using water submersion fatigue tests, Construction and Building Materials 23 (12) (2009) 3475 3484.

[6] C. Hazaree, H. Ceylan, K. Wang, Influences of mixture composition on properties and freeze-thaw resistance of rcc, Construction and Building Materials 25 (1) (2011) 313 - 319

[7] S. Roels, J. Carmeliet, H. Hens, O. Adan, H. Brocken, R. Cerny, Z. Pavlik, A. T. Ellis, C. Hall, K. Kumaran, L. Pel, R. Plagge, A comparison of different techniques to quantify moisture content profiles in porous building materials, Journal of Building Physics 27 (4) (2004) 261.

[8] K. Hansen, S. Jensen, L. Gerward, K. Singh, Dual-energy X-ray absorptiometry for the simultaneous determination of density and moisture content in porous structural materials, in: Proceedings of the 5th Symposium on Building Physics in the Nordic Countries, Vol. 1, Gothenburg, Sweden, 1999, pp. 281-288.

[9] D. Bentz, M. Geiker, K. Hansen, Shrinkage-reducing admixtures and early-age desiccation in cement pastes and mortars, Cement and Concrete Research 31 (7) (2001) 1075-1085.

[10] J. Hu, P. Stroeven, X-ray absorption study of drying cement paste and mortar, Cement and Concrete Research 33 (3) (2003) 397-403.

[11] A. Bayer, H.-J. Vogel, R. K., Direct measurement of the soil water retention curve using $\mathrm{X}$-ray absorption, Hydrology and Earth System Sciences 8 (1) (2004) 2-7.

[12] R. Baettig, R. Rémond, P. Perré, Measuring moisture content profiles in a board during drying: a polychromatic X-ray system interfaced with a vacuum/pressure laboratory kiln, Wood Science and Technology 40 (4) (2006) 261-274.

[13] P. Lura, D. P. Bentz, D. A. Lange, K. Kovler, A. Bentur, K. Van Breugel, Measurement of water transport from saturated pumice aggregates to hardening cement paste, Materials and Structures/Materiaux et Constructions 39 (293) (2006) 861868.

[14] S. Roels, J. Carmeliet, Analysis of moisture flow in porous materials using microfocus X-ray radiography, International Journal of Heat and Mass Transfer 49 (25) (2006) 4762-4772.

[15] P. H. Baker, D. Bailly, M. Campbell, G. H. Galbraith, R. C. McLean, N. Poffa, C. H. Sanders, The application of X-ray absorption to building moisture transport studies, Measurement 40 (9-10) (2007) 951-959.

[16] B. Pease, J. Couch, M. Geiker, H. Stang, J. Weiss, Assessing the portion of the crack length contributing to water sorption using X-ray absorption measurements on concrete wedge splitting specimens, in: ConcreteLife'09: Second International RILEM Workshop on Concrete Durability and Service Life Planning, Haifa, Israel, 2009. 
[17] M. Pour-Ghaz, F. Rajabipour, J. Couch, J. Weiss, Modeling fluid transport in cementitious systems with crack-like (notch) geometries, in: ConcreteLife'09: Second International RILEM Workshop on Concrete Durability and Service Life Planning, 2009.

[18] G. Sant, J. Weiss, Using X-ray absorption to assess moisture movement in cement-based materials, Journal of ASTM International 6 (9) (2009) 1-15.

[19] Z. Ye, M. Tirovic, M. Davies, P. Baker, M. Phillipson, C. Sanders, G. Galbraith, R. McLean, The testing of two methods for the moisture measurement of building fabrics via comparisons with data from an X-ray system, Building and Environment 44 (7) (2009) 1409-1417.

[20] B. Pease, Influence of concrete cracking on ingress and reinforcement corrosion, Ph.D. thesis, Technical University of Denmark, Kgs. Lyngby, Denmark (December 2010).

[21] S. Roels, K. Vandersteen, J. Carmeliet, Measuring and simulating moisture uptake in a fractured porous medium, Advances in Water Resources 26 (3) (2003) 237-246.

[22] J. Carmeliet, J.-F. Delerue, K. Vandersteen, S. Roels, Threedimensional liquid transport in concrete cracks, International Journal for Numerical and Analytical Methods in Geomechanics 28 (7) (2004) 671-688.

[23] A. Michel, B. J. Pease, M. R. Geiker, H. Stang, J. F. Olesen, Monitoring reinforcement corrosion and corrosion-induced cracking using non-destructive X-ray attenuation measurements, Cement and Concrete Research 41 (11) (2011) 1085 1094.

[24] G. Knoll, Radiation Detection and Measurement, J. Wiley, 1989.

[25] N. Tsoulfanidis, Measurement and detection of radiation, Hemisphere Publishing Corp., 1983.

[26] M. Van Geet, Optimisation of microfocus X-ray computer tomography for geological reserach with special emphasis on coal components (macerals) and fractures (cleats) characterisation, Ph.D. thesis, KU Leuven, Heverlee (April 2001).

[27] N. Dyson, X-rays in atomic and nuclear physics, Longman Scientifc \& Technical, London, 1973.

[28] T. Curry, J. Dowdey, R. Murry, Christensens Physics of Diagnostic Radiology, Lea and Febiger, London, 1990.

[29] J. Hubbell, S. Seltzer, Tables of X-ray mass attenuation coefficients and mass energy-absorption coefficients, Tech. Rep. NISTIR 5632, National Institute of Standards and Technology, Maryland, USA (2004)

[30] R. A. Brooks, G. D. Chiro, Beam hardening in X-ray reconstructive tomography, Physics in Medicine and Biology 21 (3) (1976) 390-398.

[31] J. Weiss, M. Geiker, K. Hansen, Using X-ray absorption to detect fluid ingress in cracked concrete, Tech. rep., Purdue University School of Civil Engineering, West Lafayette, IN, USA, 15 pp. (2004).

[32] C. Kleinschmidt, Analytical considerations of beam hardening in medical accelerator photon spectra, Medical Physics 26 (9) (1999) 1995-1999.

[33] J. Alles, R. F. Mudde, Beam hardening: analytical considerations of the effective attenuation coefficient of X-ray tomography, Medical Physics 34 (7) (2007) 2882-2889.

[34] www.gni.dk, GNI X-ray System, Technical University of Denmark (2010).

[35] K. Spartiotis, J. Havulinna, A. Leppänen, T. Pantsar, K. Puhakka, J. Pyyhtiä, T. Schulman, A CdTe real time X-ray imaging sensor and system, Nuclear Instruments and Methods in Physics Research Section A: Accelerators, Spectrometers, Detectors and Associated Equipment 527 (3) (2004) 478-486.

[36] K. Spartiotis, A. Leppnen, T. Pantsar, J. Pyyhti, P. Laukka, K. Muukkonen, O. Mnnist, J. Kinnari, T. Schulman, A pho- ton counting CdTe gamma- and X-ray camera, Nuclear Instruments and Methods in Physics Research Section A: Accelerators, Spectrometers, Detectors and Associated Equipment 550 (12) (2005) 267-277.

\section{Nomenclature}

$\alpha$ Fitting parameter equivalent to $a^{*} \cdot Z_{e f f}^{3.8}[-]$

$\Delta w$ Change in moisture content $\left[\mathrm{kg} / \mathrm{m}^{3}\right]$

$\eta$ Parent material coupling effect $\left[\mathrm{m}^{-1}\right]$

$\kappa$ Pair production cross-section $\left[\mathrm{m}^{-1}\right]$

$\lambda$ Beam hardening coefficient $\left[\mathrm{m}^{-1}\right]$

$\mu$ Linear attenuation coefficient $\left[\mathrm{m}^{-1}\right]$

$\mu_{0}$ Initial average attenuation coefficient $\left[\mathrm{m}^{-1}\right]$

$\mu_{w}$ Linear attenuation coefficient of water $\left[\mathrm{m}^{-1}\right]$

$\mu_{e f f, w}$ Effective attenuation coefficient of water $\left[\mathrm{m}^{-1}\right]$

$\mu_{e f f, w}(0)$ Coupled effective attenuation coefficient of water with $0 \mathrm{~m}$ thickness of parent material, fitted $\left[\mathrm{m}^{-1}\right]$

$\mu_{e f f, w}(\infty)$ Coupled effective attenuation coefficient of water with infinite thickness of parent material, fitted $\left[\mathrm{m}^{-1}\right]$

$\mu_{e f f, w}(t)$ Coupled effective attenuation coefficient of water $\left[\mathrm{m}^{-1}\right]$

$\mu_{e f f}$ Effective attenuation coefficient $\left[\mathrm{m}^{-1}\right]$

$\bar{\mu}$ Average attenuation coefficient $\left[\mathrm{m}^{-1}\right]$

$\Psi_{E}$ Shape of photon energy spectrum [-]

$\rho$ Density $\left[\mathrm{kg} / \mathrm{m}^{3}\right]$

$\rho_{w}$ Density of water $\left[\mathrm{kg} / \mathrm{m}^{3}\right]$

$\sigma$ Compton cross-section $\left[\mathrm{m}^{-1}\right]$

$\tau$ Photoelectric cross-section $\left[\mathrm{m}^{-1}\right]$

$a$ Fitting parameter describing photoelectric crosssection [-]

$a^{*}$ Fitting parameter describing effective photoelectric cross-section [-]

$b$ Fitting parameter describing photoelectric crosssection[-] 
$b^{*}$ Fitting parameter describing effective photoelectric cross-section[-]

c Fitting parameter describing Compton cross-section $[-]$

$c^{*}$ Fitting parameter describing effective Compton cross-section [-]

$C_{1-6}$ Fitting parameters [-]

$E$ X-ray photon energy $[\mathrm{keV}]$

$E_{m}$ X-ray source energy (maximum photon energy produced by polychromatic X-ray source) $[\mathrm{keV}]$

$f_{i}$ Fraction of element i [-]

I Transmitted intensity [counts]

$i$ X-ray source current $[\mu \mathrm{A}]$

$I_{0} \quad$ Initial intensity [counts]

$I_{e}$ Transmitted intensity through parent material and empty container [counts]

$I_{f}$ Transmitted intensity through parent material and container filled with water or other substance being investigated [counts]

Idry Transmitted intensity through a conditioned (dry or partially saturated) porous material [counts]

$I_{\text {wet }}$ Transmitted intensity through a wet porous material [counts]

$R_{\Delta w}$ Resolution of change in moisture content $\left[\mathrm{kg} / \mathrm{m}^{3}\right]$

$t$ Parent material (specimen) thickness [m]

$t_{w}$ Thickness of water [m]

$x$ Incremental thickness [m]

$Z_{e f f}$ Effective atomic number [-], $Z_{e f f}=\sqrt[3.8]{\sum f_{i} Z_{i}^{3.8}}$

$Z_{i}$ Atomic number of element i [-] 